\title{
Internet resources for economics
}

\author{
By Keith Morgan and Deborah Kelly-Milburn
}

\section{A cornucopia of worldwide economic indicators}

$\mathbf{N}$ ote: In all examples the home site of the information is given; however, many of these resources are "mirrored" at other sites or pointed to by local gophers. Check your local resources.

\section{Economic indicators and reports}

There are several excellent Internet collections of statistical data. This is an area that should significantly expand as more U.S. and, ideally, other national government information becomes Internet-accessible.

- Economic Bulletin Board (EBB): A firstrate example of an Internet resource that can be recommended as a research tool to patrons or used as a quick reference resource at an information desk. EBB offers the user access to thousands of data files, 700 of which are updated daily, in 22 different areas. The data are very diverse, covering such areas as employment statistics, energy shipments, the Survey of Current Manufactures datasheets, and U.S. dollar exchange rates at both $10 \mathrm{a} . \mathrm{m}$. and 12 p.m. EST, Monday to Friday. A number of software programs to aid in both viewing and working with widescreen files are available from the ftp site in compressed, binary format.

EBB is available via the University of Michigan Libraries. Files are generally updated on a daily basis, whenever possible. Four file areas are emptied at the beginning of each month; these are Trade Opportunity Program, USDA Agricultural Leads, International Market Insight
Reports, and Eastern Europe Trade Leads. $A C$ cess: Gopher "gopher.lib.umich.edu"/social sciences resources/ economics; or: Telnet "una.hh.lib.umich.edu" login as "gopher"; or: Anonymous ftp "una.hh.lib.umich.edu" /pub/.

EBB is also available directly from the Department of Commerce for a fairly modest subscription fee. As of this writing this fee-based access method requires the user to search the Commerce bulletin board system, a method far less intuitive than gopher or ftp access, which will eventually be available directly from Commerce. Access: Telnet "ebb.stat-usa.gov" login as "guest".

- National Trade Data Bank (NTDB): This valuable collection of data has been available in CD-ROM format for several years; however, on June 16 the Department of Commerce made it accessible via the Internet. Some of the many programs on NTDB include The Foreign Trader's Index, Market Research Reports, The CIA World Factbook, the complete text of the GATT and NAFTA agreements, and U.S. Industrial Outlook. There are plans for many other government agencies to disseminate information through NTDB. This includes the white House, the departments of State, Treasury, Defense, and Energy, the CIA, the International Trade Commission, and the Federal Reserve Board. Access: Gopher "gopher.stat-usa.gov"; or: WWW "http://www.stat-usa.gov/Ben/ TradePromo.html"; or: Anonymous ftp "ftp.statusa.gov".

- EconData: This is an interesting supplement to EBB. EconData consists of several hundred thousand time series datasets from both U.S. national, state, local, and international sources. All data is in compressed zip format

Keith Morgan is reference librarian and economics subject specialist at the Massachusetts Institute of Tecbnology, e-mail: kamorgan@mit.edu; Deborab Kelly-Milburn is research librarian at Harvard University, e-mail: milbum@widener1.mbs.harvard.edu 
and mounted in the $G$ data regression and model building program. There are three main file areas: Data, Tools, and Instructions. Firsttime users should get the files contents.doc, gbank.doc, and guide.doc from the Instructions directory. These files are all in ASCII format.

Examples of data available through EconData include the Annual Income and Product Accounts, Flow of Funds Accounts, Monthly National Employment, Hours, Earnings and Diffusion Indices, Producer Price and Consumer Price Indexes, and the blue pages from the Survey of Current Business. The essential advantages of EconData are the archival nature of its files and the standardized $G$ Data-Bank format. Access: Gopher "info. umd.edu" /EducationalResources/EconData; or: Anonymous ftp to "info.umd.edu" /nfo/ EconData.

- NBER: The National Bureau of Economic Research gopher provides the Penn World Tables, an expanded dataset of international comparisons as well as an index of NBER publications. The ftp site also has the Survey of Consumer Finances (62-63; 83-86; 89), NBER trade and immigration data, as well as everything on the gopher. Access: Gopher "nber.harvard.edu"; or: Anonymous ftp "nber.harvard.edu" / pub/0.

- NEEEDC: The New England Electronic Economic Data Center offers the Federal Reserve Bank of New England's Economic Indicators (1969-). Also mounted at this site is the Regional Economic Information System (REIS) CD-ROM. The data are in .PRN format and can be read directly by Lotus or Quattro. Access: Anonymous ftp "neeedc.umesbs.maine.edu" "pass" for password cd frbb (for Reserve Bank Data) cd bea (for REIS).

- Dow-Jones: For a set of Dow-Jones historical averages three files are available: 1) Dow Jones Industrial Averages, 1885-1985; 2) Date, high, low, and close for DJIA from 1952-1990; 3) DJIA close from 1900-1952. Access: Gopher "econ.lsa.umich.edu" / data/.

- Investment Data: This site contains some public domain investment finance data for the U.S. Although this is "unofficial" data, there are some interesting market data and programs. A partial listing of about 5,000 ticker symbols and a shareware copy of DC Econometrics' stock market forecasting models are just two examples of what is available here Access: Anonymous ftp "dg-rtp.dg.com" / pub/ misc.invest.
- SEC: The EDGAR project allows public access via the Internet to $10 \mathrm{Q}, 10 \mathrm{~K}$, and other financial disclosure information required by the SEC. The service is just getting started and not all companies are available; however, all publicly traded companies are required to file electronically by the end of 1995 . This means that eventually this site will contain financial data for more than 15,000 companies. Access: Gopher "town.hall.org" /SEC Edgar; or: Anonymous ftp "townhall.org" /Edgar/; or: WWW "http://town.hall.org" /edgar/edgar.html/

- Historic Price Data: A clataset of commodity price indexes from the U.K., U.S., Canada, Norway, and Sweden. U.K. numbers go back to 1600 , the U.S. to 1790 . All other countries complete from 1870 onwards. Access: Gopher "niord.shsu.edu" /economics/historic price data/.

- Statistics Canada Gopher: A new service as of February 1994, this site so far only lists the daily economic reports and the release data of new economic indicators. Available in English or French. Access: Gopher "talon.statcan.ca".

- Country Reports: The 4th annual Economic Policy and Trade Practices report from the U.S. Department of State provides detailed reports regarding the economic policies and trade practices of each country with which the U.S. has an economic or trade relationship. Each report is divided into nine areas and includes such information as key economic indicators, exchange rate policies, debt management policies, and an assessment of protections available for U.S. intellectual property. Access: Gopher "umslvma.umsl.edu" /library/govdocs/

- Labor Statistics: LABSTAT, the Bureau of Labor Statistics' public database, provides current and historical data for 25 surveys. These include such databases as comprehensive Consumer Price Index data, International Labor Statistics, The Producer Price Index, and Employment Cost Index. See the file "overview.doc" in the "doc" directory for information on file storage. Access: Anonymous ftp "ftp.bls.gov" /pub/ time.series.

- Federal Reserve Bank: This site contains information from the Federal Reserve Board's statistical release series. Data such as the Flow of Funds Tables, Reserves of Depository Institutions, Selected Interest Rates, and other money stock measures and components are available. Access: Gopher "town.hall.org" Federal Reserve; or: Anonymous ftp 
"townhall.org" /other/fed/; or: WwW "http:// town.hall.org/other/fed/".

- Social Security Administration: The electronic information system of the Office of Social Security offers the complete Current Operating Statistics from the Social Security Bulletin and selected information from the data tables in the Annual Statistical Supplement. Access: Gopher "oss968.ssa.gov"; or: Anonymous ftp "soaf1.ssa.gov" /pub/; or: WWW "http:// www.ssa.gov/SSA_Home.html".

- Federal Deposit Insurance Corporation: There are three valuable datasets on the FDIC gopher: The Statistics on Banking, 1991; The Statistics on Banking, 1992; The Historical Statistics on Banking, 1934-1992. Also, in the Consumer Information Directory is information on the Bank Rating Services, consumer rights, and insured deposits. Data files are primarily in Lotus 123 .WK1 format; text files are in both ASCII and WordPerfect 5.1. Access: Gopher "fdic.sura.net 71".

- Bank of England: The Bank of England Quarterly Bulletin time series data can be searched at this site. Access is very slow. $A c$ cess: Telnet "sun.nsf.ac.uk" login: "janet" hostname: "uk.ac.swurcc" username: press [send] which service: PMAC [and] select 3 from the menu.

- U.K. Central Statistical Office: This site offers a search and extraction system for the Central Statistical Office's Macro-Economic Time Series data. Access is also very slow. Access: Telnet "sun.nsf.ac.uk" login "janet" hostname: "uk.ac.swurcc" username: press [send] which service: PMAC [and] select 1 from the menu.

\section{Private datasets}

An interesting use of the Internet has arisen as authors mount complementary economic datasets that relate to their own books and articles. Four recent examples are:

- John Abowd and Richard Freeman's edition of the NBER Project Research Report Immigration, Trade and the Labor Market (University of Chicago Press, 1991). Access: Gopher "nber.harvard.edu" /pub/trade.immigration.

- The dataset associated with David Backus and Patrick Kehoe's "International Evidence of the Historical Properties of Business Cycles," American Economic Review 82 (September 1992). Access: Anonymous ftp "uts.mcc.ac.uk" /pub/Krichel/DatEc.

- Gauss programs and datasets for count models and duration regression models associ- ated with Gary King and Andrew Gelman's research, particularly in King's Unifying Political Methodology (Cambridge University Press, 1989). Access: Anonymous ftp "haavelmo. harvard.edu" pub/count; pub/judgeit; pub/ maxlink.

- The Penn World Tables dataset discussed in Robert Summer and Alan Heston's "The Penn World Table (Mark 5): An Expanded Set of International Comparisons," Quarterly Journal of Economics 106 (May 1991). Access: Anonymous ftp "nber.harvard.edu /pub/pwt55/.

\section{Software libraries}

- Many economics articles are written with the LaTeX typesetting program. Several archive sites have style files that correspond with various journal requirements. Bibliographic style files for the American Economic Review, the Canadian Joumal of Economics, and others are available. Access: Gopher "pip.shsu.edu" Economics/EconBib.

- The Netlib archive is a library of mathematical software and databases. The programs originated in various U.S. research labs and are generally of very high quality. Most are written in Fortran but some other languages, particularly $\mathrm{C}$ and $\mathrm{C}++$, are now available. Some wellknown numerical software are on this site, including Linpack, Eispack, and Lapack. There are a number of sites available, several of which are listed below. Access: Gopher "wuecon.wustl.edu" /Washington University Economics Gopher/ NetLib/; or: Anonymous ftp "netlib2.cs.utk.edu".

- The Statlib archive of statistical software contains a large collection of statistics, data, directory lists, and random material. Statlib contains the source code to entire statistics packages such as XlispStat. This site is probably not as valuable to economists as Netlib. Access: Gopher "lib.stat.cmu.edu"; or: ftp "lib.stat.cmu.edu" (login as "statlib", not anonymous).

\section{Working papers}

Like many academic disciplines, economics disseminates preliminary research through the preprint process of working papers. Several projects have begun to use the Internet as a wider and more efficient transmission medium. Three noteworthy projects are:

- The NetEc project: This is an attempt to assemble an extensive bibliography of current working papers in economics from depart- 
ments all over the world (BibEc), in addition to an archive collection of the working papers (WoPEc). Access: Gopher "uts.mcc.ac.uk" /Economics - NetEc/; or: Telnet "uts.mcc.ac.uk" login in as "NetEc"; or: Anonymous ftp "uts.mcc.ac.uk" / pub/ NetEc/.

- The Econ-wp archive: This is a project of the University of Washington at St. Louis that provides an Internet site for storing and accessing working papers in economics. The site is arranged according to the classification scheme from the Journal of Economic Literature. The Web server will display papers in PostScript format. Access: Gopher "econwpa.wustl.edu"; or: WWW "http:// econwpa.wustl.edu/Welcome.html".

- The University of Michigan (UM) Department of Economics: This gopher server has a directory of UM department working papers as well as a directory of working papers related to the economics of the Internet. Access: Gopher "econ.Isa.umich.edu" /working papers/; or: WWW "http://gopher.econ. Isa.umich.eduEconInternet.html".

\section{Newsgroups}

The newsgroup "sci.econ" is the main Usenet Economics related newsgroup for general discussion. A moderated newsgroup, "sci.econ.research" was created in June 1993. Other newsgroups of interest to economists include:

- comp.text.tex: the TeX typesetting system

- misc.invest: investment finance

- sci.stat.math: statistics and math

- sci.stat.edu: statistics and education

- comp-soft.sys: SAS

- comp-soft.sys.spss: SPSS

- comp-soft.sys.shazam: the Shazam statistics package

- The archives of several groups can be found on the Journal of Statistics Education gopher at North Carolina State University. These include SAS-L; SPSSx-L; Stat-L; and Chance. ACcess: Gopher "jise.stat.ncsu.edu" /Other Discussion Groups/.

- For the archives of Pol-Econ and FedTaxL: Access: Gopher "niord.shsu.edu" / Economics (SHSU Network Access Initiative Project)/ Archives of Pol-Econ, FedTax-L, and sci.econ.research/.

\section{Finding other resources}

This is a very selective guide to resources on the Internet for economists. Since economics is such a pervasive discipline, you can be sure that the number of Internet resources will continue to grow. A guide such as this can only touch on some of the more pertinent sites; other guides are available on the network. A gopher at the University of Michigan maintains a clearinghouse of subject-oriented Internet resource guides, including several for economists. A particularly noteworthy guide is Bill Goffe's "Resources for Economists on the Internet." Access: Gopher "una.hh.lib.umich.edu" / inetdirs.

It is a sad fact of life on the network, however, that as soon as most guides are published, they are already out of date. For those who wish to search for current economics information on the Internet, gophers provide easy access. There are a number of gophers that have grouped information by subject (subject trees) and the gopher at Michigan State University provides an excellent starting place, connecting to over 20 different locations. The subject tree at Rice University is especially useful, with well over 100 resources accessible. Access: Gopher "burrow. cl.msu.edu" /network \& database resources/ internet by subject.

For the scholar searching for a particular piece of information on the Internet, Veronica and Jughead are the best tools for the novice. Both provide keyword indexing of gopher menus, allowing the user to pinpoint very specific information. Jughead searches only a specific group of gopher menus, and usually provides better, faster results. Veronica casts the widest possible net. Many gophers allow Veronica searches; the best site for Jughead is at Washington and Lee University. Access: Gopher "liberty.uc.wlu.edu" /finding gopher resources/search high-level gopher menus by jughead. The Washington and Lee site is a very popular one and it is often difficult to connect directly to it. Sometimes accessing it through another site, such as U.C. Santa Cruz, works best. Access: Gopher "scilibx.ucsc.edu" /the world/other internet gopher servers/ jughead.

In order to make a comprehensive search of the Internet, the user must search Archie. Archie indexes the vast information residing at ftp sites around the globe. You can telnet to Archie sites at a variety of locations or submit requests by e-mail. In either case, Archie requires specific commands. 

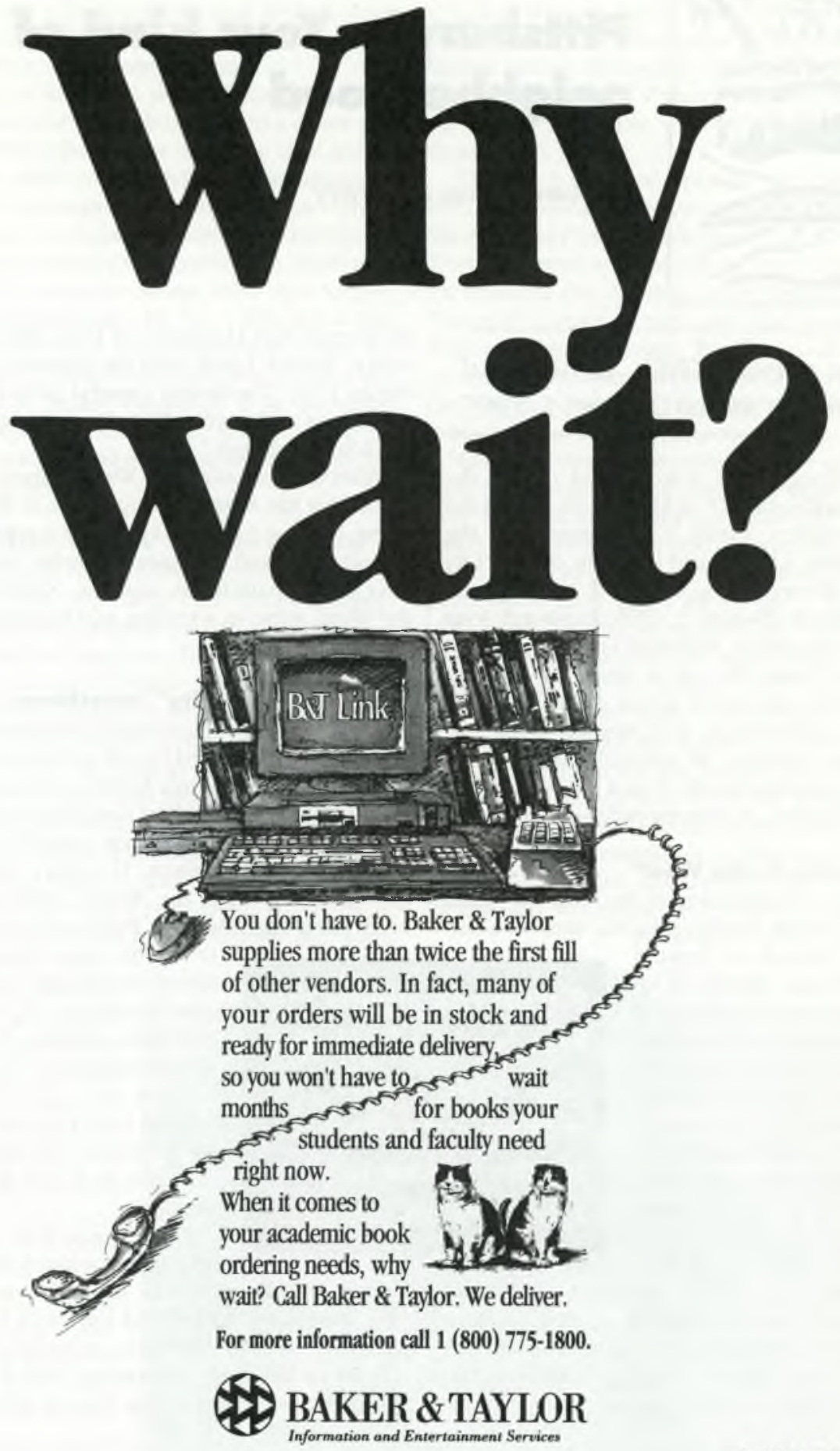